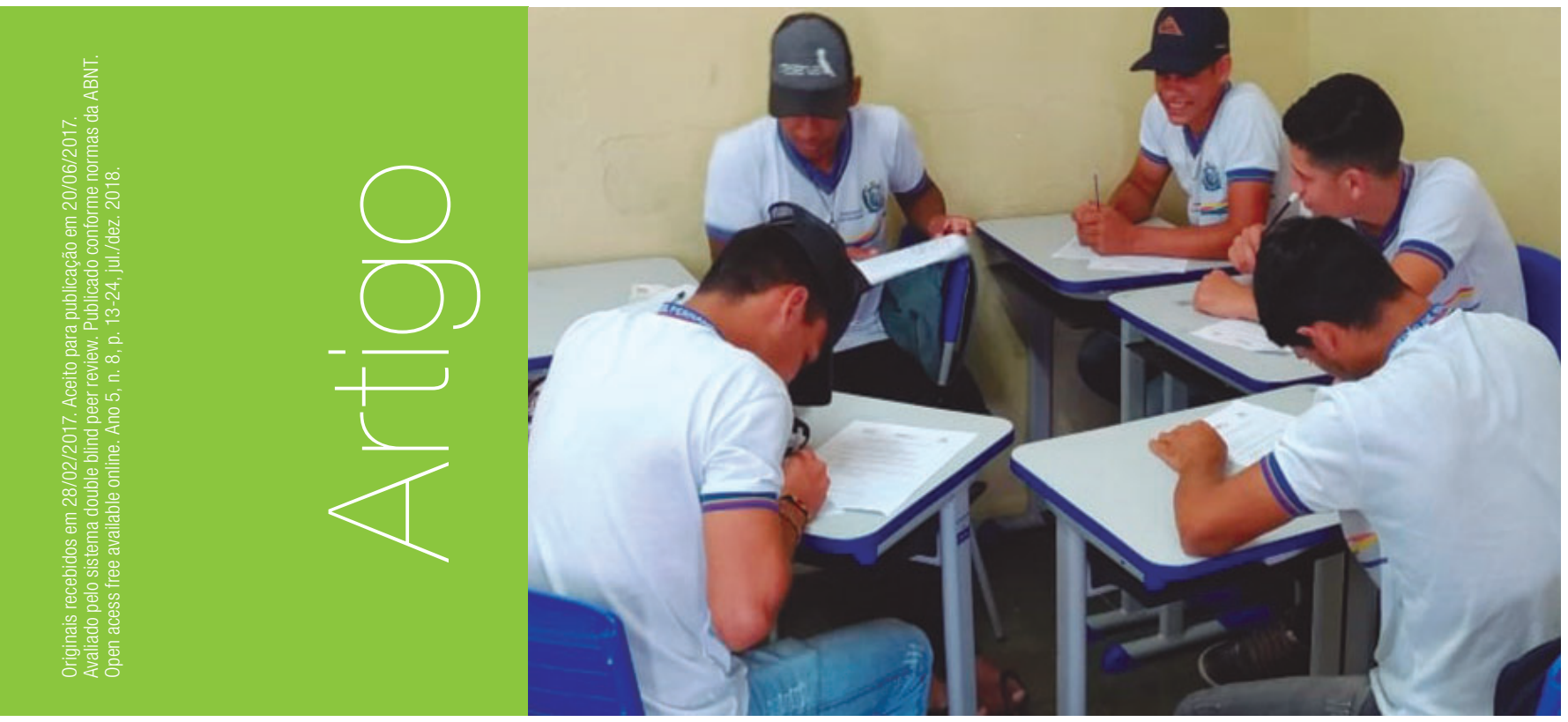

\title{
Educação em Saúde na Escola: Vivência com Estudantes do Sexo Masculino de Escolas Públicas
}

\author{
Maria Isabelle Barbosa da Silva Brito - isabellebrito94@gmail.com \\ Jéssica Kelly Coutinho de Melo² - jk_kelinha@hotmail.com \\ Valéria Alexandre do Nascimento ${ }^{3}$ - valeria.nascimento11@hotmail.com \\ Yasmim Guimarães Tavares ${ }^{4}$ - yasmim.tavares01@gmail.com
}

\section{RESUMO}

0 objetivo do estudo foi desenvolver a autonomia nos indivíduos do sexo masculino em questões de saúde, através de intervenções educativas, utilizando a metodologia de Círculos de Cultura, sob a perspectiva Paulo Freire. Foi realizada uma pesquisa-ação em quatro escolas públicas da cidade do Recife/PE, com cerca de 70 adolescentes do sexo masculino, estudantes do ensino médio. A pesquisa obteve aprovação do Comitê de Ética em Pesquisa do Complexo Hospitalar HUOC/PROCAPE (CAAE no 18295713.2.0000.5192), recebendo parecer favorável $\left(n^{0}\right.$ 563.770). As intervenções foram compostas por cinco encontros, cada um deles abordando

1 Enfermeira pela Universidade de Pernambuco (UPE). Recife, PE, Brasil. Residente em Saúde Coletiva pelo Instituto Aggeu Magalhães (IAM)/FIOCRUZ-PE. Recife, PE, Brasil

2 Enfermeira pela Universidade de Pernambuco (UPE). Recife, PE, Brasil. Residente em Enfermagem Obstétrica pela Escola de Governo em Saúde Pública de Pernambuco (ESPPE). Recife, PE, Brasil.

3 Enfermeira pela Universidade de Pernambuco (UPE). Recife, PE, Brasil. Residente em Saúde da Família pela Universidade Federal de Pernambuco (UFPE). Recife, PE, Brasil.

4 Enfermeira pela Universidade de Pernambuco (UPE). Especialista em Gestão e Auditoria em Sistemas de Saúde. Recife, PE, Brasil. 
temáticas como: níveis de atenção à saúde; sexualidade e paternidade precoce; violência; consumo de álcool e outras drogas e alimentação saudável. Pôde-se perceber a importância da desconstrução da ideia de invulnerabilidade do homem e possibilitar aos mesmos a expressão de seus medos e fragilidades, para que se sintam mais confortáveis em procurar ajuda.

\section{PALAVRAS-CHAVE}

Círculos de cultura. Estudantes. Saúde do homem. Educação em saúde.

\section{ABSTRACT}

The objective of the study was to develop autonomy in the male subjects in health issues, through educational interventions, using the Circles of Culture methodology, under the Paulo Freire perspective. An action research was conducted in four public schools in the city of Recife / PE, with about 70 male adolescents, high school students. The research was approved by the Research Ethics Committee of the Hospital Complex HUOC / PROCAPE (CAAE $n^{\circ}$ 18295713.2.0000.5192), receiving a favorable opinion ( $n^{0}$ 563.770). The interventions were composed of five meetings, each addressing topics such as: health care levels; sexuality and early paternity; violence; consumption of alcohol and other drugs and healthy eating. It was possible to perceive the importance of deconstructing the idea of invulnerability of man and to enable them to express their fears and weaknesses, so that they feel more comfortable in seeking help.

\section{KEYWORDS}

Crop circles. Students. Human health. Health education.

\section{Introdução}

A adolescência, transição entre infância e idade adulta, é um período único, caracterizado por marcantes transformações anatômicas, fisiológicas, psicológicas e sociais, estando a personalidade em fase final de estruturação. Alguns adolescentes conseguem lidar bem com essa situação de modificações, enquanto outros sofrem grande estresse e se submetem a atitudes de risco que podem afetar seu bem estar (NAU et al., 2013).

0 método pedagógico de Paulo Freire possibilita aos jovens o papel de sujeito do processo educativo proposto e valoriza as fontes culturais e históricas dos indivíduos, que podem ser desveladas nos Círculos de Cultura. Este é um termo criado por Freire, representado por um espaço dinâmico de aprendizagem e troca de conhecimentos, e é uma opção capaz de promover o processo de aprendizado em diversas áreas, inclusive da saúde, permitindo o levantamento e reflexão dos temas vividos pelos participantes. Estes se reúnem no processo de educação para investigar temas de interesse do próprio grupo. Representa uma situação-problema de situações reais, que leva à reflexão da própria realidade, para, na sequência, decodificá-la e reconhecê-la (NAU et al., 2013).

Os Círculos de Cultura tiveram grande aplicabilidade na alfabetização de adultos, no exercício pedagógico de Paulo Freire, iniciado na década de 60 . Constituem uma ideia que substitui a de "turma de alunos" ou de "sala de aula". A escolha por desenvolver um Círculo de Cultura tem a finalidade de ensejar uma vivência participativa com ênfase no diálogo e uma educação em saúde emancipatória. Estabelecendo uma estratégia da educação libertadora, o Círculo de Cultura é um lugar onde todos têm a expressão, onde todos leem e escrevem o mundo. É um espaço de trabalho, pesquisa, exposição de práticas, dinâmicas, vivências que possibilitam a elaboração coletiva do conhecimento (MONTEIRO; VIEIRA, 2010). Estudos científicos têm evidenciado maior vulnerabilidade dos homens ao desenvolvimento de doenças graves e crônicas, quando comparados às mulheres, além de apresentarem maior índice de mortalidade precoce (NARDI et al., 2007; COURTENAY, 2007; IDB, 2006 LAURENTI et al., 2005; LUCK et al. 2000). Apesar disso, os homens não costumam buscar os serviços de atenção primária e grande parte dessa 
resistência está relacionada a variáveis culturais. Os estereótipos de gênero presentes há séculos em nossa cultura patriarcal induzem práticas baseadas em crenças e valores do que é ser masculino. Além disso, os serviços e as estratégias de comunicação privilegiam as ações de saúde para a criança, 0 adolescente, a mulher e o idoso (BRASIL, 2009a).

Verifica-se que a maioria dos homens acessa os serviços de saúde por meio da atenção terciária, quando já existe um quadro clínico de morbidade instalado, muitas vezes cronificado, demandando altos custos sociais e econômicos. Assim, incluir os homens na atenção à saúde é um desafio às políticas públicas, pois estes não reconhecem a importância da promoção da saúde e prevenção de doenças como questões associadas a sua saúde. 0 cuidar de si e a valorização do corpo no sentido da saúde não são questões colocadas na socialização dos homens. Como consequência, pode-se afirmar que esta construção sociocultural do ser humano tem produzido comportamentos e atitudes que influenciam negativamente nos seus determinantes do processo saúde-doença (MOREIRA et al., 2014).

0 potencial das ações de promoção da saúde na infância e adolescência é enorme. A infância e a adolescência são períodos do desenvolvimento humano no qual se estabelece o comportamento, caráter, personalidade e estilo de vida, e 0 ambiente em que o jovem está inserido é um dos principais fatores influenciadores (CARVALHO, 2012).

0 ambiente escolar constitui-se como um importante espaço para formação cidadã de adolescentes, preparando-os para conviver e agir em sociedade mediante mecanismos de sociabilidade e integração entre as diferentes visões de mundo (BRANDÃO NETO et al., 2014). Dessa forma, é possível traçar ações que busquem interligar educação e saúde com o objetivo de mobilizar e beneficiar a comunidade do sexo masculino (BRASIL, 2009b).

Devido à maior vulnerabilidade da população masculina no que diz respeito a doenças e agravos à saúde, torna-se evidente a necessidade de ações educativas para promoção da saúde de adolescentes do sexo masculino, justificando, assim, a realização deste estudo, que tem por objetivo desenvolver autonomia nos indivíduos do sexo masculino através de intervenções educativas, utilizando a metodologia de Círculos de Cultura proposta por Paulo Freire.

\section{Caminhos metodológicos}

0 estudo teve base no Relatório Final do Projeto de Extensão intitulado Saúde do Homem no Cenário Escolar, desenvolvido com o apoio da Pró-Reitoria de Extensão e Cultura da Universidade de Pernambuco (PROEC/UPE), vigente de maio de 2013 a fevereiro de 2014. Trata-se de um método qualitativo, do tipo pesquisa-ação, fundamentado na metodologia de Círculos de Cultura proposta por Paulo Freire.

Os Círculos de Cultura constituem um espaço de encontro e descoberta do outro como sujeito, com aspirações, sentimentos e vivências que precisam ser desveladas a partir do diálogo no grupo, da participação nas discussões e da troca de conhecimento e experiências (MONTEIR0; VIEIRA, 2010).

Os Círculos de Cultura na sua dimensão epistemológica podem perfeitamente se circunscrever no marco da pesquisa-ação, pois ela é um tipo de pesquisa social, com base empírica que é concebida e realizada em estreita associação com uma ação ou com a resolução de um problema coletivo, e na qual os pesquisadores e os integrantes da situação ou do problema estão envolvidos de modo cooperativo ou participativo (THIOLLENT, 2007).

0 estudo foi realizado em quatro escolas públicas estaduais localizadas no bairro de Santo Amaro, Recife-PE, Brasil. Após autorização formal e escrita obtida na Gerência Regional de Educação Recife Norte (GRE - Recife Norte), as declarações foram encaminhadas às unidades escolares, para que as direções das mesmas tomassem conhecimento do estudo que seria desenvolvido. Antes de dar início às atividades, o projeto foi apresentado em cada sala de aula, momento em que também foi entregue o Termo de Consentimento Livre e Esclarecido (TCLE), para que cada estudante menor de 18 anos obtivesse autorização dos pais ou responsáveis para participar da pesquisa. 
A amostra foi constituída por aproximadamente setenta alunos do sexo masculino, regularmente matriculados no ensino médio e que se enquadravam nos critérios de inclusão: 1) Estudantes do sexo masculino que frequentavam a escola no turno da manhã e/ou tarde; 2) Que se disponibilizaram a participar dos encontros; 3) Que obtiveram o TCLE assinado pelos pais ou responsáveis.

0 estudo foi composto por cinco etapas (MELLO et al., 2012):

1) Planejamento: Através de pesquisas bibliográficas foi possível identificar quais as principais problemáticas que atingem adolescentes do sexo masculino e, com base nos achados, elaborar um Círculo de Cultura com o objetivo de obter a opinião e conhecimento dos alunos sobre tais temáticas.

2) Coleta de Dados: Realização do Círculo de Cultura elaborado na etapa de planejamento e registro dos relatos obtidos.

3) Análise de Dados e Planejamento: Tabulação das falas obtidas e identificação das principais necessidades dos alunos. Posteriormente, foram planejadas as atividades e temáticas a serem trabalhadas nos próximos encontros.

4) Implementação de Ações: Desenvolvimento dos Círculos de Cultura para trabalhar as principais temáticas propostas e coletar falas e expressões dos alunos acerca de suas dúvidas e anseios.

5) Avaliação dos Resultados e Construção de Relatório: Avaliação, através das falas dos alunos, da eficácia das atividades. Posteriormente foi redigido o relatório final da pesquisa.

0 estudo atendeu às determinações preconizadas pela Resolução n 466/2012 do Conselho Nacional de Saúde (CNS), que normatiza as pesquisas envolvendo seres humanos e foi aprovado pelo Comitê de Ética em Pesquisa da Universidade de Pernambuco, com parecer de n $n^{0} 563.770$ e registro CAAE: 18295713.2.0000.5192.

\section{Resultados}

Em cada escola, as intervenções foram compostas por cinco encontros, cada um deles abordando as seguintes temáticas: níveis de atenção à saúde; sexualidade e paternidade precoce; violência; consumo de álcool e outras drogas e alimentação saudável. Entre as dinâmicas utilizadas para trabalhar cada tema, pode-se citar a utilização de questionários para debate; atividades lúdicas com recortes e colagens; uso de imagens e textos (Figuras 1-3). Ao final do estudo, foi feita uma síntese de toda a vivência, para comparar o conhecimento e opinião dos alunos antes e após a realização das atividades.

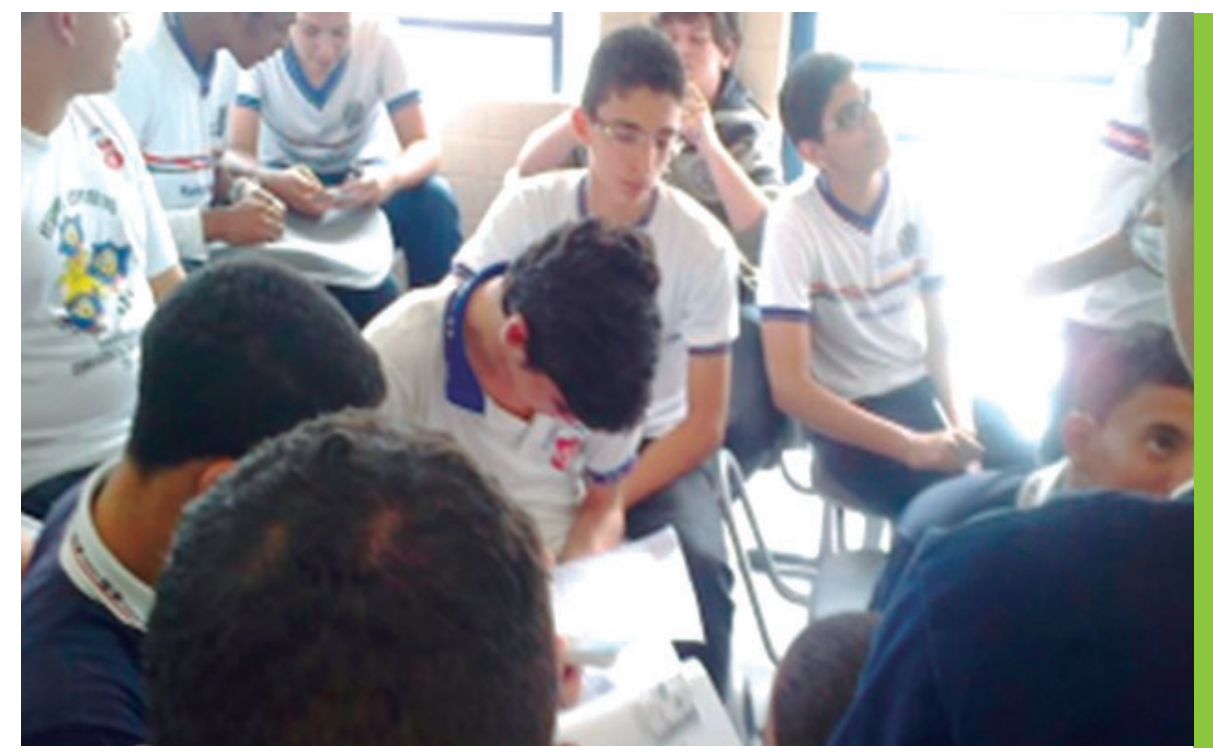

Figura 1: Alunos utilizando uma das dinâmicas escolhidas para atividade. 
Figura 2: Alunos utilizando uma das dinâmicas escolhidas para atividade.

Fonte: Dados desta Pesquisa.

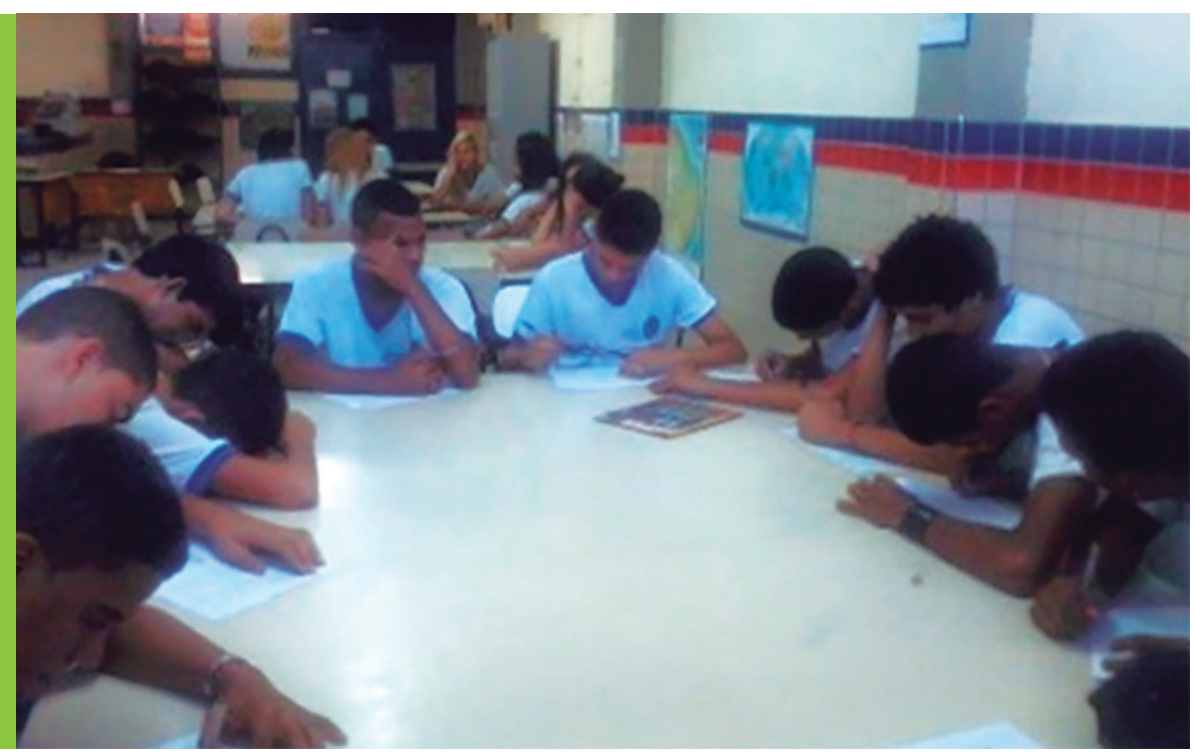

Figura 3: Alunos utilizando uma das dinâmicas escolhidas para atividade.

Fonte: Dados desta Pesquisa.

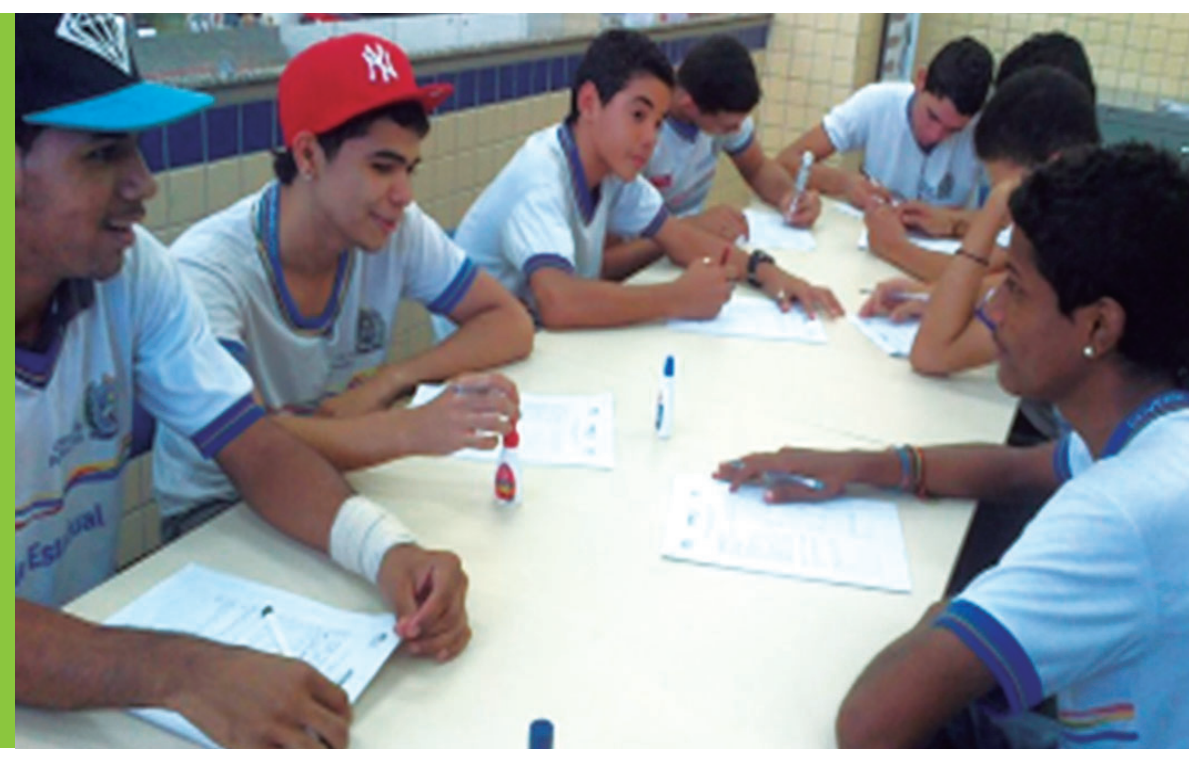

$1^{0}$ encontro: Momento para estabelecer o primeiro contato com os estudantes e avaliar 0 conhecimento dos mesmos sobre as temáticas escolhidas para compor os Círculos de Cultura. Foram selecionadas algumas falas que se destacaram durante 0 encontro.

Quando questionados se a mulher deve ter mais cuidado com a saúde do que o homem, relataram:

A mulher deve ter mais cuidado, porque tem maior fragilidade imunológica. (J.R., 19 anos)

A mulher tem mais tendência para adoecer... (I.S., 16 anos)

As mulheres devem se cuidar mais, porque são mais sensiveis. (T.M., 17 anos)

Sobre sexualidade e paternidade precoce:

Eu não costumo usar preservativo nas minhas relações sexuais... (S.F.S., 17 anos)

Eu estaria preparado pra ser pai, pois sou maduro o bastante e estou preparado psicologicamente. (E.V., 18 anos)

Não costumo conversar com meus pais sobre sexo e a importância de se prevenir... (G.A., 16 anos)

Em relação à violência, afirmaram:

Já agredi meus amigos psicologicamente por motivos banais. (R.V.S., 17 anos) 
Briguei pra ajudar o outro cara que estava comigo. (I.N., 16 anos)

Sobre consumo de álcool e outras drogas:

Gosto de beber, porque ficamos mais animados! (A.S., 16 anos)

A vida é simples demais sem fumar e sem beber. (A.G., 16 anos)

De droga ilícita, eu já usei maconha e loló... (C.H., 17 anos)

Quando indagados sobre alimentação saudável:

Uma má alimentação pode ocasionar sangue fraco. (T.J.,16 anos)

Todos os dias eu lancho biscoito e guaraná... (V.E., 14 anos)

Uma alimentação saudável é comer uma salada básica no almoço e frutas. (L.R.N., 17 anos)

$2^{0}$ encontro: Neste encontro foi realizada a primeira intervenção. Foi abordada a temática de níveis de atenção à saúde. Através de recortes e colagens, os estudantes foram colocados em situações práticas, e posteriormente, foram questionados sobre qual o nível de atenção (primário, secundário ou terciário) procurariam em tais situações. Diante do sentimento de invulnerabilidade da população masculina, foi enfatizado o espaço que existe para a prevenção de doenças, e não apenas para a intervenção das existentes. Por fim, foi destacada a importância de manter uma alimentação saudável e do uso de preservativos durante as relações sexuais, exercitando sempre a autonomia dos estudantes como responsáveis por sua própria saúde.

$3^{\circ}$ encontro: A temática escolhida para 0 terceiro encontro foi sexualidade e paternidade precoce. Foram utilizados textos com depoimentos de adolescentes que foram pais precocemente e questionado os estudantes sobre a temática. 0 objetivo foi conscientizar sobre a responsabilidade de ser pai e a importância do planejamento familiar. No debate sobre sexualidade, foi destacada a importância do uso de preservativos durante as relações sexuais e a importância de conhecer as doenças sexualmente transmissiveis e as formas de transmissão. Foram utilizadas imagens e definições dessas doenças, para que os alunos pudessem associálas e, a partir disso, puderam-se esclarecer as dúvidas existentes sobre a temática.

$4^{0}$ encontro: Os temas escolhidos para serem debatidos no quarto encontro foram violência e consumo de álcool e drogas. Os alunos foram indagados sobre o que entendiam como violência. Muitos associavam apenas com a violência física, sem se atentar as outras formas, como a verbal. Através de uma conversa, os pesquisadores puderam conscientizar os estudantes sobre os danos causados pela agressão verbal e física, que são bastante frequentes nas escolas. Os pesquisadores estimularam a conscientização dos alunos, fazendo com que eles refletissem como seria estar na condição de vítima. Para abordar sobre consumo de álcool e drogas, foi solicitado que os estudantes elaborassem uma lista com os pontos que eles consideravam positivos e negativos do consumo. 0 objetivo foi demonstrar a prevalência de pontos negativos e as consequências físicas e sociais que o consumo de álcool e drogas pode acarretar.

$\mathbf{5}^{\circ}$ encontro: Para debater sobre alimentação saudável, foi disponibilizada uma cadeia alimentar, a qual os estudantes precisaram preencher de acordo com a sua alimentação diária. A partir disso, foram debatidos os malefícios que certos alimentos causam à saúde e as opções para substituí-los e manter uma alimentação saudável. Por fim, houve o encerramento das atividades, na qual os alunos puderam expressar os benefícios da troca de experiências e saberes realizada no decorrer dos encontros. Observou-se uma melhora da concepção dos alunos, quando comparado com o primeiro Círculo de Cultura realizado. Foram destacadas algumas falas, que confirmaram uma mudança benéfica significativa:

Agora sempre uso preservativo, porque além de evitar filhos, me previno de doenças. (C.C., 18 anos)

Ser pai não é só ter o filho e pronto. Para ser pai, deve-se ter uma estabilidade financeira e psicológica para ajudar na criação do filho. (A.G., 17 anos) 
Já pratiquei violência psicológica na escola, mas hoje eu vejo como era idiota... (H.R.S., 17 anos)

Não vejo motivo pra me embriagar quando eu posso aproveitar outros prazeres da vida. (A.P., 16 anos)

Acho que agora não preciso beber, e sim estudar... (M.H.O., 14 anos)

Uma má alimentação pode causar várias doenças, como pressão alta, diabetes, obesidade... (H.F., 17 anos)

\section{Discussão}

0 primeiro encontro nas escolas foi um momento oportuno para identificar o conhecimento dos estudantes sobre os níveis de atenção à saúde; sexualidade e paternidade precoce; violência; consumo de álcool e outras drogas e alimentação saudável. Através dos relatos, foi perceptível a existência de limitações de informação sobre as temáticas que os alunos traziam, confirmando a suscetibilidade às doenças que o sexo masculino sofre.

Por meio das respostas dos estudantes é possível afirmar que eles traziam consigo a ideia do sexo masculino ser intangível às doenças, principalmente quando comparados às mulheres. Esse achado é condizente com a alarmante epidemiologia encontrada nos altos índices de morbimortalidade e a resistência que a população masculina brasileira tem em procurar os serviços de saúde, visto que estar doente e buscar a atenção básica é considerado um sinal de fragilidade do sexo masculino, contribuindo assim para que o homem se julgue invulnerável em todos seus ciclos vitais (CAMARGO et al, 2011; DUARTE; SOUZA, 2012).

Os adolescentes devem encontrar auxílio em um ambiente aberto para o diálogo, dúvidas, descobertas, medos e carências, no qual eles possam suprir as inseguranças, a descrença, para potencialmente tornarem-se capazes de se autogerir dentro de uma sociedade. A escola é um desses ambientes; porém, os alunos mostraram que mesmo estando diariamente no ambiente escolar, e mesmo sendo alertados sobre os riscos iminentes para a saúde, os professores não conseguem convencê-los a mudarem seus hábitos e pensamentos (REIS; SILVA, 2009).

Por isso, percebe-se que a promoção da saúde no ambiente escolar precisa ser efetivada com parcerias, abandonando o antigo modelo de educação, onde apenas a figura do professor é o centro do ensino. Os alunos, as famílias, os profissionais de saúde e os educadores devem ser dotados de pensamentos voltados para as reais necessidades da população. Dessa forma, a interdisciplinaridade ganha espaço, e a escola passa a ser um palco para transformações de pensamento e construção de saúde dentro do seu contexto social (COSTA; SILVA; DINIZ, 2008).

No segundo encontro foram explicados e detalhados cada nível de atenção à saúde e qual deles deve ser recorrido em cada situação específica. Os estudantes mostraram ser conhecedores dos serviços que existem e quais devem buscar, porém, afirmaram não frequentá-los, apenas quando não há outra alternativa. É perceptível que há uma dissonância entre o que se conhece para que o cuidado à saúde possa ser eficaz e o que é efetivamente praticado. Esse dado vai de encontro com alguns estudos que apontam a prevalência do sexo masculino na procura dos serviços de emergência, farmácia e o pronto-socorro, por serem mais rápidos e terem acesso mais fácil (GOMES; NASCIMENTO; ARAÚJO, 2007).

Quando se compara a procura dos serviços de saúde entre homens e mulheres, observa-se que a resistência do sexo masculino é bem maior que a do sexo feminino. Isso torna-se um problema de saúde pública, de modo na maioria das vezes em que os serviços de saúde são buscados pelos homens, já se tem um quadro clínico de morbidade crônica instalado, podendo levar à morte (STARFIELD, 2004).

A necessidade de priorizar a saúde masculina como uma meta para as políticas públicas colaborou para o desenvolvimento da Política Nacional de Atenção Integral à Saúde do Homem (PNAISH). 
Os profissionais são conhecedores da vulnerabilidade do homem, por isso precisam praticar a PNAISH o mais precocemente e reduzir as complicações para saúde do homem (STARFIELD, 2004). É esperado que, a partir da execução dessa política, ocorra uma modificação na forma dos homens lidarem com a própria saúde e, com isso, os indicadores epidemiológicos nacionais que comparam morbimortalidade masculina e feminina sejam diminuídos (FONTES et al, 2011).

No terceiro encontro pôde-se observar o quanto os adolescentes estão iniciando sua atividade sexual cada vez mais cedo, o que possibilita 0 aumento das consequências imediatas dessa sexualização infanto-juvenil, como por exemplo as doenças sexualmente transmissíveis e a paternidade precoce (UTIAMADA, 2012).

Quando questionados sobre 0 uso de preservativos, alguns estudantes afirmaram não utilizá-Ios, 0 que torna 0 quadro ainda mais preocupante. Alguns também afirmaram estar preparados para assumir um filho, o que comprova a falta de conhecimento acerca da enorme responsabilidade de ser pai.

Ser adolescente e ser pai dificilmente serão condições complementares. Isso indica que os adolescentes experimentariam mais eventos estressores do que os adultos ao se depararem com a paternidade. As possíveis causas desta situação estressora estariam relacionadas à imaturidade psicológica e à falta de condições estruturais para lidar com a nova fase. Diante disso, os adolescentes precisam assumir responsabilidades e desempenhar papéis que estariam fora de seus planos de vida imediatos (MEINCKE; CARRARO, 2009).

A violência no cenário escolar tem crescido significativamente nos últimos anos, apresentando diversas situações conflituosas, sendo a agressão física por meio de brigas a manifestação mais corriqueira da violência interpessoal (MALTA, 2010). Quando indagados sobre 0 conceito de violência, os alunos associaram-na primeiramente à violência física, por relacionarem esta às agressões físicas e por ser a forma mais comum entre eles. Os alunos usaram da naturalidade ao exibirem a frequência dos atos agressivos que acontecem na escola.

Porém, quando as pesquisadoras expuseram o conceito de violência e apresentaram seus diferentes tipos, enfatizando a violência verbal, que é comum no meio escolar, os alunos puderam perceber que também a praticavam no dia-a-dia. A existência de outras formas de violência não deve ser esquecida, visto que quando um aluno é vítima de qualquer forma de violência, isso interfere em sua autoestima, no processo de aprendizagem e nas interações sociais, podendo causar um sentimento de revolta, tornando-0 assim um ser agressivo (MONTEIRO; VIEIRA, 2010).

É na escola que as atitudes de constrangimento a que os jovens são submetidos ganham ênfase, pois ocasionam impactos no desenvolvimento do alvo e em diversos âmbitos da vida deles (MONTEIRO; VIEIRA, 2010). Os relatos da identificação com a prática do bullying se assemelha a outros estudos (MALTA, 2010; MONTEIRO; VIEIRA, 2010). Que utilizaram os achados da Pesquisa Nacional de Saúde do Escolar, onde, com relação ao gênero, a pesquisa apontou uma frequência maior entre os indivíduos do sexo masculino envolvidos.

Para que exista uma redução de atos violentos nas escolas, é necessário que se tenha o respeito entre os alunos e que aconteçam debates constantes sobre esta problemática, fazendo com que haja uma frequente reflexão crítica sobre os malefícios causados por práticas que antes eram vistas como inofensivas.

Quando questionados sobre consumo de álcool e outras drogas, os jovens associaram essas substâncias a momentos de diversão, como festas e comemorações. A cultura de preponderância masculina e a associação do álcool aos momentos de folga, lazer, relaxamento e descontração exercem forte influência para que essa realidade seja estabelecida.

Estudos mostram que entre as drogas mais utilizadas estão o álcool (68,9\%), tabaco (22,7\%), solventes (10,1\%), maconha (6,6\%), ansiolíticos (3,8\%), anfetaminas (2,6\%) e cocaína (1,6\%). E destacam o sexo masculino como maior consumidor (GUIMARÃES, 2004).

Muitos adolescentes consomem álcool e outras drogas sem que seus pais saibam ou, em outros casos, o problema encontra-se em casa, quando um parente é quem incentiva o consumo. 
Pesquisas apontam que 0 uso nocivo de álcool pelos pais e a falha no controle e supervisão sobre 0 consumo dos filhos expressam 0 aumento do risco de uso nocivo e dependência na idade adulta (GRUNBAUM et al, 2004; KUNTSCHE, REHM; GMEL, 2004).

0 consumo de álcool e outras drogas é um dos principais fatores que acarretam a vulnerabilidade na adolescência, através, por exemplo, dos suicídios, violência, acidentes, transmissão de doenças por via sexual e endovenosa, nos casos das drogas injetáveis, e a gravidez não planejada. Além disso, ainda existe outra problemática atrelada ao consumo de drogas, que é o seu uso nas escolas, sendo, no Brasil e em outros países, risco para estabilidade social (VENDRAME, 2009).

A maioria dos estudantes relataram ser consumidores das drogas lícitas, ilícitas ou de ambas. Diferentes estudos epidemiológicos trazem o estudante do sexo masculino como predominante quanto ao consumo de álcool e outras drogas (STRAUCH et al, 2009; GALDURÓZ et al, 2010). Essa realidade comprovada por nosso estudo torna necessária que haja ações preventivas a partir de políticas públicas e articulação de escolas com os serviços de saúde para que problemas oriundos da exposição precoce dos adolescentes ao álcool sejam evitados.

No último encontro foram abordadas questões relacionadas à alimentação. Uma alimentação saudável contribui para 0 adequado crescimento e desenvolvimento, bem como para reduzir os riscos de doenças relacionadas à má nutrição (GALDURÓZ et al., 2010; LEME, PHILIPPI; TOASSA, 2013). Os adolescentes passam uma boa parte do seu dia nas escolas e assim precisam se alimentar de alguma forma, às vezes de forma inadequada. Por exemplo, no recreio algumas escolas fornecem merendas, que na maioria das vezes é saudável, mas alguns preferem ir à cantina e comprar uma coxinha com refrigerante. Com isso, os problemas de saúde como a obesidade só fazem aumentar. Alguns adolescentes citaram não gostar da merenda por que era sempre a mesma coisa todos os dias e eles enjoavam. Percebemos que muitos deles não sabiam de fato o que era uma alimentação saudável, sua importância e seus benefícios. Depois de explicada a dinâmica da pirâmide alimentar, pôde-se observar a mudança benéfica de alguns pensamentos para melhor, vale salientar. Por fim, fechamos o encontro com uma discussão integrando todas as temáticas vistas anteriormente e percebemos o quanto foi proveitoso para os alunos esses encontros. Ficou nítido como a informação é importante para a sociedade, percebemos como as ideias e os pensamentos de cada um mudou para melhor.

\section{Conclusão}

Este estudo proporcionou a vivência dos participantes nos Círculos de Cultura, sendo um momento de encontro e descoberta do outro como sujeito, com anseios, sentimentos e vivências que precisam ser reconhecidas a partir do diálogo em grupo, da participação nas discussões, da troca de conhecimentos e experiências.

Com tais vivências, pôde-se concluir a importância da desconstrução da ideia de invulnerabilidade do homem e possibilitar aos mesmos a expressão de seus medos, ansiedades, fragilidades, para que estes se sintam mais acolhidos e confortáveis para procurar ajuda às suas questões de saúde.

Evidenciou-se que a execução do Círculo de Cultura permitiu que os adolescentes explorassem e discutissem sobre diversos temas. Esse fato favoreceu a harmonia e o envolvimento entre os participantes do círculo.

Observou-se como é importante o aprendizado emergir do próprio grupo, pois eles se perceberam no seu contexto e puderam refletir sobre sua própria realidade. Vale ressaltar que pelo fato deste grupo ser composto apenas por meninos, estes se sentiram mais à vontade para abordarem assuntos peculiares do seu universo.

Em suas falas foi evidente que os estudantes estavam pouco esclarecidos sobre alguns temas que foram abordados no início dos encontros. Porém, no transcorrer das intervenções foi perceptível uma mudança de entendimento dos mesmos. 
A complexidade dos determinantes de saúde nos conduz à necessidade de investigações nesta área de conhecimento, visando promover ações educativas que sejam capazes de agir sobre o indivíduo. Dessa forma, criando e ampliando suas potencialidades para inserir-se nos grupos que o englobem e em redes sociais, abrindo-se para experiências coletivas através do diálogo, construindo uma consciência coletiva para impulsionar mudanças, exercendo seu papel no controle social.

Foi constatado com este estudo que são necessárias ações de educação em saúde, como o Círculo de Cultura, que propiciem os jovens expor suas dúvidas e conhecer os meios de prevenção, capacitando-os a repensar condutas, favorecendo uma melhor qualidade de vida e sendo um método eficaz para a aprendizagem.

\section{Referências}

BRANDÃO, NETO et al. Intervenção educativa sobre violência com adolescentes: possibilidade para a enfermagem no contexto escolar. Escola Anna Nery Revista de Enfermagem, v. 18, n. 2, p. 195-201, 2014.

BRASIL. Política Nacional de Atenção Integral à Saúde do Homem: princípios e diretrizes. Brasília: Ministério da Saúde, 2009a. Disponível em: http://bvsms.saude.gov.br/bvs/ publicacoes/politica_nacional_atencao_homem.pdf. Acesso em 8 jan. 2018.

BRASIL. Caderno de Atenção Básica: Saúde na Escola. Brasília: Ministério da Saúde, 2009b. Disponível em: http://189.28.128.100/dab/docs/publicacoes/cadernos_ab/abcad24. pdf. Acesso em 8 jan. 2018.

CAMARGO, Brigido et al. Representações sociais de saúde e cuidado: um estudo multicêntrico sobre vulnerabilidade masculina. Temas Psicol, v.19, n. 1, p. 179-192, 2011.

CARVALHO, F. F. B. A saúde na escola e a Promoção da Saúde: conhecendo a dinâmica intersetorial em Duque de Caxias e Nova Iguaçu - RJ. 2012. Dissertação (Mestrado em Saúde Pública) - FIOCRUZ - Fundação Oswaldo Cruz, Rio de Janeiro.

COSTA, Felipe; SILVA, Jorge; DINIZ, Marcia. A Importância da Interface EducaçãolSaúde no Ambiente Escolar como Prática de Promoção da Saúde. Informe-se em promoção da saúde, v.4, n.2. p.30-33, 2008.

COURTENAY WH. Constructions of masculinity and their influence on men's welleing: a theory of gender and health. Soc Sci Med, 50:1385-401, 2000.

DUARTE, Sebastião; OLIVEIRA, Juliano. A Política Saúde do Homem e sua operacionalização na Atenção Primária à Saúde. Rev Eletr Gestão Saúde, v.3, n. 1, p. 308-317, 2012.

FONTES, Wilma et al. Atenção à saúde do homem: interlocução entre ensino e serviço. Acta Paul Enferm, v.24, n. 3, p.430-433, 2011.

GALDURÓZ, José et al. Fatores associados ao uso pesado de álcool entre estudantes das capitais brasileiras. Rev. Saúde Pública, v.44, n. 2, p.267-273, 2010.

GOMES, Romeu; NASCIMENTO, Elaine. Por que os homens buscam menos os serviços de saúde do que as mulheres? As explicações de homens com baixa escolaridade e homens com ensino superior. Cadernos de Saúde Pública, v.23, n.2, p.565-574, 2007.

KUNTSCHE, E.; REHM, J. Characteristics of binge drinkers in Europe. Soc Sci Med, v. 59, n. 1, p.113-127, 2004.

LAURENTI RUY et al. Perfil epidemiológico da morbi-mortalidade masculina. Ciência Saúde

Coletiva, 10:35-46, 2005. 
LUCK, M; BAMFORD, M. Men's health: perspectives, diversity and paradox. London: Blackwell Sciences; 2000.

LEME, A; PHILIPPI, S. 0 que os adolescentes preferem: os alimentos da escola ou os alimentos competitivos? Saúde Soc, v.22, n.2, p. 456-467, 2013.

MALTA, Debora et al. C. Vivência de violência entre escolares brasileiros: resultados da Pesquisa Nacional de Saúde do Escolar (PeNSE). Cienc. saude colet, v.15, n. 2, p. 30533063, 2010.

MEINCKE, Sonia; CARRARO, Telma. Vivência da Paternidade na Adolescência: Sentimentos Expressos pela Família do Pai Adolescente. Texto Contexto Enferm, v. 18, n. 1, p.83-91, 2009.

MELLO, Carlos et al. Pesquisa-ação na engenharia da produção: proposta de estruturação para sua condução. Produção, v.22, n. 1, p. 1-13, 2012.

MONTEIRO, Estela; VIEIRA, Neiva. Educação em saúde a partir de círculos de cultura. Rev. bras. enferm., v.63, n. 3, p.397-403, 2010.

MOREIRA, R.L.S.F.; FONTES, W.D.; BARBOZA, T.M. Dificuldades de inserção do homem na atenção básica a saúde. Escola Anna Nery Revista de Enfermagem, v.18, n.4 , p.615621, 2014.

NAU, A. L. et al. Educação Sexual de Adolescentes na Perspectiva Freireana Através dos Círculos de Cultura. Revista da Rede de Enfermagem do Nordeste - Rev Rene, v.14, n. 5, p. 886-893, 2013.

NARDI, Aguinaildo et al. Primeiro Estudo Epidemiológico sobre Câncer de Pênis no Brasil. International Braz J Urol, v. 33, p. 1-7, 2007.

REIS, Franklin; SILVA, Anderson. Adolescência: Consumo de Álcool e Outras Drogas. Revista Enfermagem Integrada, v. 2, n. 1, p. 112-125, 2009.

STARFIELD, B. Atenção primária: equilíbrio entre necessidades de saúde, serviços e tecnologia. Brasília: Ministério da Saúde, 2004. Disponível em: http://bvsms.saude.gov.br/bvs/ publicacoes/atencao_primaria_p1.pdf. Acesso em 8 jan.2018.

STRAUCH, Eliane et al. Uso de álcool por adolescentes: estudo de base populacional. Rev. Saúde Pública, v.43, n.4, p. 647-655, 2009.

THIOLLENT, M. Metodologia da pesquisa-ação. 15. ed. São Paulo: Cortez, 2007.

UTIAMADA, M. A paternidade na adolescência: um estudo a partir da visão dos pais adolescentes do ambulatório de pré-natal do Hospital de Clínicas de Londrina. Anais do I Simpósio sobre Estudos de Gênero e Políticas Públicas. 2010, Londrina, p. 38-48.

VENDRAME, A et al. Apreciação de propagandas de cerveja por adolescentes: relações com a exposição prévia às mesmas e o consumo de álcool. Cad. Saúde Pública, v.25, n. 2, p.359365, 2009. 